\title{
Application of Multiple Intelligence Theory in Exhibition Occupation Education
}

\author{
Bei Jin \\ Beijing City University, Beijing, 100083, China \\ email: shuimujinbei@126.com
}

Keywords: Exhibition occupation education; Multiple intelligence; personnel training

\begin{abstract}
Although the exhibition occupation education in China started relatively late, but it is developing very fast. In the crucial period of its development, as a new opportunity and challenge to occupation education, how to meet market demand for professionals, avoid education risk and training technical personnel characteristic, the reasonable exhibition occupation education has become a hot topic. Based on the multiple intelligence theory, this paper will give an specific intelligence characteristics analysis for students who involved in the exhibition professional study, and according to the requirements of practitioners in the market experience, puts forward a new multiple intelligence thinking and planning on exhibition occupation education model, as one of practical application in China's Occupation education system.
\end{abstract}

\section{Introduction}

Multiple intelligence theory is proposed by Howard Gardner who is an American famous educator and psychologist of Harvard University. According to Gardiner's view: the purpose of school education should be developed more intelligent and help students to find suitable for the intelligent features of the occupation and hobbies[1,2]. This theoretical study to carry out, in the past ten years, has made an important contribution to the occupation education idea transformation of China's tradition, play a important role in promoting the development of China's occupation education.

In the past ten years, by the rapid development of City Convention and exhibition industry, the demand of exhibition personnel increases year by year, that delivered many multi-level exhibition education. Although the education of exhibition occupation started late in China, but its rapid development at a high starting point, and is a product of the multiple exhibition market demand, this determines the diversification and modular personnel occupation education training, the curriculum attributes setting based on the occupation development, the curriculum contents designing based on the actual exhibition process and actual project oriented, the intelligent evaluation based on different education object, so carrying out occupation education personnel training from features of multiple intelligence talent view is very important to promote the development of occupation education. This paper attempts to using the multiple intelligence personnel occupation education concept, summarize and analyze intelligence talent view application status in the occupation education of exhibition in China, by combined with the talent demand and development features of China's convention and exhibition industry and the present situation of higher occupation education, will carry out the new thinking on the application of multiple intelligence personnel in occupation education of exhibition.

\section{Establishing exhibition occupation education target}

According to the multiple intelligence theory as the basis, comparing the enrollment occupation education teaching object with the ordinary undergraduate education, we know that it has a big difference lies in the college entrance examination scores, usually the students who involved in occupation education are relatively weak in logical mathematical intelligence respects under the college entrance examination standards which pay more attention to the language intelligent, but that doesn't mean they are weak in other intelligence. Studies have shown that intelligent type of 
occupation education objects have "action" advantage, that is fit to carry out for practice teaching[3,4]. The early stages of development of occupation education of exhibition emphasizes the cultivation of a large number of skilled talents for the demand of convention and exhibition industry, universities and colleges should make full use of the special intelligent type advantage of occupation education object, focus on cultivating the practical ability of students[5]. By the end of 2012, China's exhibition occupation education institutions have reached more than 100 at a very rapid development. At present the overall model of exhibition education in our country is similar to that of United States of America, in most of colleges and universities the exhibition occupation education is vocational, secondary or at the university occupation training department, while the construction of talent training mode is more learning German mode, develop the features intelligence of students, emphasize the cultivation of students' occupation skills, and carry out school-enterprise cooperation for professional co-construction, which provide demonstration and experience for us to make good occupation education exhibition.

\section{Avoiding homogenization of exhibition occupation education and ordinary undergraduate education}

In recent years, with the development of applied undergraduate, many university and college have offered professional exhibition with majority named with "professional exhibition planning and management", mostly the curriculum is also similar, under this influence it makes a homogenization trend of exhibition occupation education to ordinary undergraduate education, reflected in the aspects of professional named, the curriculum setting and the textbook selection.This makes the occupation education lost its own advantages of focusing on practicality training, as well as advantage of students in the employment competition. How to highlight the characteristics of occupation education? At first it need to make evaluation of intelligent type accurately, make clear must be in the traditional concept of talent evaluation, development the characteristic and advantage of occupation education, accurate positioning market demand, education object clear advantage, cultivate occupation education personnel talent.

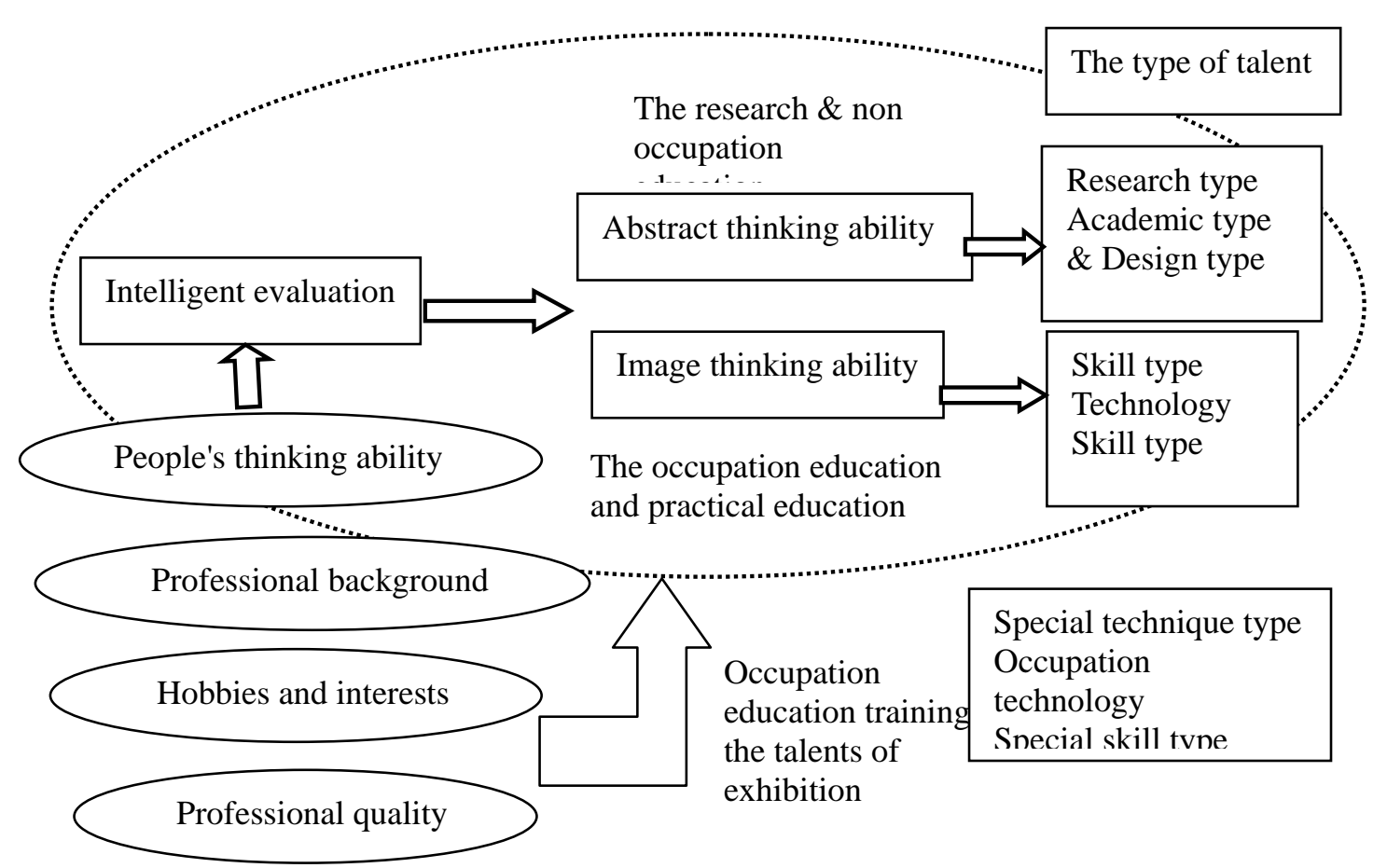

Fig.1 Muti-intelligent type evaluation of exhibition occupation education talent 
Fig.1 proposed the intelligent type suitable for exhibition talents training based on the classical theory of multiple intelligence type divided. Dotted area is the traditional human thinking ability for the intelligent evaluation method evaluation factors, students who are good at abstract thinking ability are proper to be cultivated as research, academic or special design talents by present record of formal schooling and research education system. While students who are good at the image of thinking ability are fit for education for the occupation education and application type by occupation education system. So avoiding homogenization of exhibition occupation education and ordinary undergraduate education is very important. Because the exhibition works have more elements of humanities and civilization, to exhibition occupation education object, it needs to add more intelligent evaluation factors. Apart from the traditional types of intelligence division of the ability of abstract thinking and image thinking ability, the intelligent evaluation of exhibition occupation education should be more combined with the special characteristics of the exhibition industry and the talent demand, according to students basic professional background, personal interests and hobbies, knowledge and art to give a integrated intelligent evaluation, based on the exact muti-intelligent evaluation, set characteristics curriculum and teaching methods. In this way, it is advantageous to promote individual potential of the education object, more stress the occupation education characteristics and get the best education results.

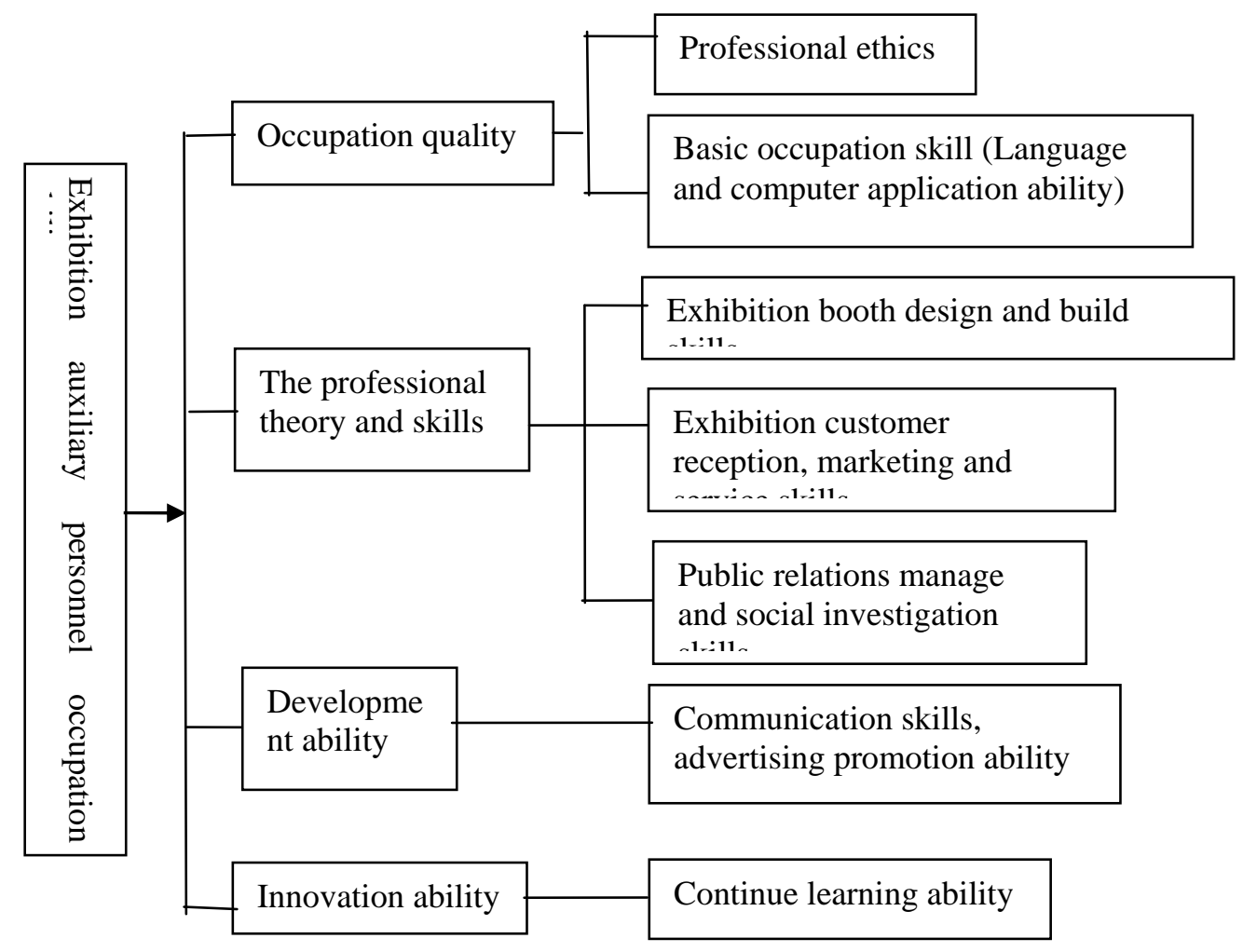

Fig.2 Mode of multiple intelligent talents training of exhibition occupation education

\section{Emphasizing occupation ability training, constructing multiple talents raining model for the exhibition occupation education}

Convention and exhibition industry require practitioners have strong practical ability, this decide the exhibition occupation education aims to train practical and professional talent, during training process it must involve the practice teaching segment. But due to the mature model of school-enterprise cooperation and alternation of teaching-practical working which is suitable for China's industry and education reality has not been achieved, most colleges and universities are in the exploratory stage. Some universities practice teaching only stay on the surface, or become a mere formality, so the role of improving and enhancing students practical ability is not obvious. At 
the same time as the blindness of expansion of running universities, many colleges and universities which engaged in the exhibition occupation education are lack of analysis on talent market demand of occupation personnel ability, have no comprehensive evaluation of muti intelligent type of teaching object, this lead to the practice of teaching is not pertinence, adaptability is not high, as well the teaching can not achieve good results. It is generally believed that the exhibition talent is divided into three levels as core talent, auxiliary personnel, support personnel, now goal of exhibition occupation education is to provide assist personnel for huge demand of the exhibition industry, the works post is focused on the design and construction of exhibition booth, customer service, exhibition marketing, exhibition reception, social investigation, and public relations management. In line with the respect to the multiple intelligence type of occupation education object, to solve the fundamental problems of practice teaching, with only starting from the perspective of demand in the job occupation ability, a cultivation mode of multiple intelligent talents cultivating about exhibition occupation education is established as Fig.2

\section{Conclusion}

By the rapid development of convention and exhibition industry in China, it needs many professional skills talents. Occupation education is the very proper pattern to cultivate this type of talent. Based on current situation of Chinese education structure and enrollment of new students studying at the occupation education, to meet the exhibition market demand of talents and occupation, it must establishing the new education model using multiple intelligence theory. Investigation show that at first it need to make evaluation of intelligent type accurately, then carrying muti intelligent education mode design. The proposed intelligent education way which focusing on practical ability training is more suit for cultivating skillful talents to meet the demand of convention and exhibition industry.

\section{Acknowledgement}

The author gratefully acknowledge the financial support of the Teaching and education project (Research on new teaching mode as working and studying alternation for exhibition major of higher occupation professional education , JYC201122) of Beijing City University .

\section{References}

[1] P.Parker, S.N. Khapova, M.B.Arthur. The intelligent career framework as a basis for interdisciplinary inquiry[J]. Journal of Vocational Behavior, 200975 291-302.

[2] E.S.Dottin. Professional judgment and dispositions in teacher education[J]. Teaching and Teacher Education, 200925 83-88.

[3] K.Knipfer, E.Mayr, C.Zahn, S.Schwan, F.W. Hesse. Computer support for knowledge communication in science exhibitions: Novel perspectives from research on collaborative learning[J]. Educational Research Review, 2009, 4 196-209.

[4] P.Cartier. Most valuable aspects of educational expectations of the students in design education[J]. Procedia-Social and Behavioral Sciences, 201115 2187-2191.

[5] V.S. McCabe. Strategies for career planning and development in the Convention and Exhibition industry in Australia[J]. International Journal of Hospitality Management, 200827 222-231. 